\title{
A Novel Design of UHF RFID Passive Tag Antenna Targeting Smart Cards Limited Area
}

\author{
Mahreen Riaz \\ School of Engineering \\ London South Bank \\ University \\ United Kingdom \\ Email: riazm4@1sbu.ac.uk
}

\author{
Grzegorz Rymar \\ School of Engineering \\ London South Bank \\ University \\ United Kingdom
}

\author{
Mohammad Ghavami \\ School of Engineering \\ London South Bank \\ University \\ United Kingdom
}

\author{
Sandra Dudley \\ School of Engineering \\ London South Bank \\ University \\ United Kingdom
}

\begin{abstract}
The aim of this paper is to design an Ultra High Frequency (UHF) Radio Frequency Identification (RFID) passive tag antenna to fit in the limited space of smart cards, such as bankcards, along with contactless payment facility and Europay, MasterCard and Visa (EMV) chip. In this paper, UHF tag antenna is designed using Monza R6 chip specifications from Impinj manufacturers while focusing on high performance and read ranges of upto 12 meters with very small sized antenna dimensions of $17.9 \times 47.30 \mathrm{~mm}^{2}$. Performance is analysed in terms of gain, read ranges and power reflection coefficients. UHF tag antenna is designed using aluminium on Polyethylene Terephthalate (PET) substrate. The proposed design aims to meet objectives of low cost and small size while maintaining high performance.
\end{abstract}

Keywords: RFID, UHF, Passive tag antenna, smart cards, Polyethylene Terephthalate (PET)

\section{INTRODUCTION}

RFID is emerging as one of the most popular technology for many potential applications such as medical inventory, customer service, retail inventory, asset management, operational configuration and object identification by using active, semi-active or passive chipped UHF tag antennas. Globally UHF frequency range is from $860-960 \mathrm{MHz}$ while the European frequency region is from $865.6-867.6 \mathrm{MHz}$. RFID technology is also rapidly gaining interest in scientific and commercial sectors due to many key features [1]-[2]. It is basically used for identifying physical objects through Radio Frequency (RF) radiations and is referred as Automatic Identification System[3]. RFID takes an advantage over barcode systems due to non-line-of-sight identification.

RFID system consists of an RFID reader, RFID tag and a host computer to manage the information as shown in Fig.1. Reader consists of an RF transceiver module, coupling element (antenna), controller unit and signal processor, and a serial interface to connect with the host computer. RFID tag consists of resonant tuned antenna and a low power CMOS IC[4]. This technique involves in the contactless reading and writing of data into the non-volatile memory of RFID tag through back scattered RF signals. The voltage which develops across the antenna terminal power up the chip and sends back information to the reader by varying the input impedance and modulating backscattered signals[5].
Some of the major factors that affect the responsiveness of a tag are impedance mismatch between tag antenna and chip, communication blind spots, multipath fading and orientation and location of tag within the RFID environment [6]. To acheive the maximum efficiency and read range, special attention should be paid to the design of the tag antenna[2]-[5].

In the past literature, many RFID tag antennas are designed using different substrates and metallic track materials [6]-[7]. Different tag antennas are designed based on different chips available in the market to operate at UHF frequency band regions [3]-[9] however, most of them are larger enough to fit in small areas such as bankcards with limited free space.

In this paper, the focus of our investigation is to design a tag antenna on PET substrate using aluminum etching that works at EU frequency band region with small size to ensure the placement in bank card as shown in Fig.2. The impedance of the tag antenna is matched with Monza R6 chip along with maintaining high read rates and performance. The rest of the paper is divided into the following sections: The second section introduces antenna design parameters, the third section represents the tag antenna design and characterization, the forth section presents results and discussion carried out using CST software platform, and the fifth section concludes this paper.

\section{Antenna Design Parameters}

The UHF tag antenna design should have a high gain, isotropic radiation properties and impedance matching with the chip to ensure maximum power transfer as shown in 1 [10].

$$
Z_{\text {ant }}=Z^{*}{ }_{\text {chip }}
$$

$Z_{\text {ant }}$ indicates the impedance of the UHF tag antenna while, $Z^{*}{ }_{\text {chip }}$ shows the complex conjugate of the input impedance of the chip [8]. As microchips store energy so their input reactance shows a high capacitive behaviour. RFID UHF microchips mostly exhibit imaginary input reactance ranging from -70 to $-400 \Omega$, while the real part is mostly within $50 \Omega$. Thus, for impedance matching tag antenna should have 
TABLE II

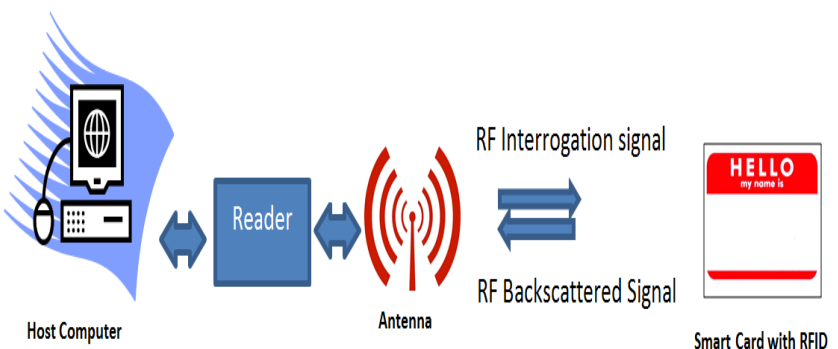

Fig. 1. RFID System Block Diagram

inductive impedance to achieve complex impedance matching. If antenna parameters are known, it is possible to calculate the RFID tag antenna read range as shown in 2 [8]:

$$
r=\frac{\lambda}{4 \pi} \sqrt{\frac{P_{T} G_{T} G_{R} \tau}{P_{t h}}}
$$

Here, $\lambda$ is the wavelength, $P_{T}$ is the power transmitted by the reader, $G_{T}$ is the gain of the transmitting antenna, the product of $P_{T} G_{T}$ is equivalent to EIRP, the effective radiated power of the reader, $G_{R}$ is the gain of the receiving tag antenna, $P_{t h}$ is the minimum threshold power to activate the RFID tag chip. Whereas, $\tau$ is defined as the power transmission coefficient shown as [10]:

$$
\text { tau }=\frac{4 R_{\text {chip }} R_{\text {ant }}}{\left|Z_{\text {chip }}+Z_{\text {ant }}\right|^{2}} \quad 0 \leq \tau \leq 1
$$

$Z_{\text {chip }}=R_{\text {chip }}+j X_{\text {chip }}$ is the impedance of the chip and $Z_{\text {ant }}=R_{\text {ant }}+j X_{\text {ant }}$ is the impedance of the tag antenna. Every country has its own regulations that specifies the UHF RFID frequency transmission ranges within that country. According to the latest regulatory status of RFID in the EPC Gen2 (860-960 MHz) band, the frequency ranges of RFID transmission in some countries are shown in TABLE1 [11]:

TABLE I

UHF BANd Frequency and Power Allocation

\begin{tabular}{|c|c|c|}
\hline Country/Region & $\begin{array}{c}\text { Frequency Range } \\
(\mathrm{MHz})\end{array}$ & $\begin{array}{c}\text { Frequency Range } \\
\text { (W ERP) }\end{array}$ \\
\hline Europe & $865.6-867.6915-921$ & 4 \\
\hline USA & $902-928$ & 4 \\
\hline China & $920.5-924.5$ & 2 \\
\hline Japan & $916.7-920.9$ & 4 \\
\hline
\end{tabular}

Recently, in November 16, another frequency band of 915$921 \mathrm{MHz}$ is allocated to European region[11].

\section{UHF TAG ANTENNA DESIGN CHARACTERIZATION}

The tag antenna design is the most complex stage in passive UHF RFID systems. As mentioned before, the tag antenna transfers radiated energy from reader antenna to the chip to turn it on. The current UHF tag design is optimized to work with the commercial Monza R6 chip from Impinj manufacturers. TABLE2 is showing the chip parameters [12]:

\begin{tabular}{|c|c|c|c|c|}
\hline $\begin{array}{c}C_{p} \\
(\mathrm{pF})\end{array}$ & $\begin{array}{c}R_{p} \\
(\Omega)\end{array}$ & $\begin{array}{c}C_{\text {mount }} \\
(\mathrm{pf})\end{array}$ & $\begin{array}{c}\text { ChipReadSensitivity } \\
(\mathrm{dBm})\end{array}$ & $\begin{array}{c}C_{\text {mount }} \\
(\mathrm{dBm})\end{array}$ \\
\hline 1.23 & 1.2 & 0.21 & -20 & -16.7 \\
\hline
\end{tabular}

Where, $C_{p}$ is parallel chip capacitance, $R_{p}$ is the parallel resistance of chip. $C_{\text {mount }}$ is defined as the typical capacitance due to adhesive mount parasitics. The total load capacitance offered to antenna model is $C_{T}=C_{p}+C_{\text {mount }}$. Impedance of the chip is calculated using $R_{p}, C_{p}$ and $C_{\text {mount }}$ by the using following equations:

$$
\begin{gathered}
R_{\text {chip }}=\frac{\left(R_{1} R_{2}-X_{1} X_{2}\right)\left(R_{1}+R_{2}\right)+\left(X_{1} R_{2}+X_{2} R_{1}\right)\left(X_{1}+X_{2}\right)}{\left(R_{1}+R_{2}\right)^{2}+\left(X_{1}+X_{2}\right)^{2}} \\
X_{c h i p}=\frac{\left(X_{1} R_{2}+X_{2} R_{1}\right)\left(R_{1}+R_{2}\right)-\left(R_{1} R_{2}-X_{1} X_{2}\right)\left(X_{1}+X_{2}\right)}{\left(R_{1}+R_{2}\right)^{2}+\left(X_{1}+X_{2}\right)^{2}} \\
Z_{\text {equ }}=\frac{Z_{1} Z_{2}}{Z_{1}+Z_{2}}=\frac{\left(R_{1}+j X_{1}\right)\left(R_{2}+j X_{2}\right)}{\left(R_{1}+R_{2}\right)\left(X_{1}+X_{2}\right)}=R_{c h i p}+j X_{c h i p}
\end{gathered}
$$

Here, $R_{1}=1200 \Omega, X_{1}=0, R_{2}=0$ and $X_{2}=j 128 \Omega$, the equivalent chip impedance is calculated as:

$$
Z_{e q u}=13.5-j 126.56 \Omega
$$

To achieve maximum power transfer from tag antenna to chip, the real part of tag antenna impedance $R_{a n t}$ should be equal to the real part of chip impedance $R_{\text {chip }}$, likewise the complex part of tag antenna impedance $X_{\text {ant }}$ should be a complex conjugate of the chip impedance $X_{\text {chip }}$ as shown in 1. Fig.2 represents the layout of the smart card available area for UHF tag, the red lines are showing the NFC tag tracks around the bank card, yellow lines are depicting the free available space for RFID UHF tag while, the green coloured hatched area is showing the area occupied by the EMV chip and card embossment. As the UHF tag antenna geometry is dipole so for symmetrical design the rectangular blue hatched area is allocated for UHF tag design with area of $20.41 \times 50.41 \mathrm{~mm}^{2}$.

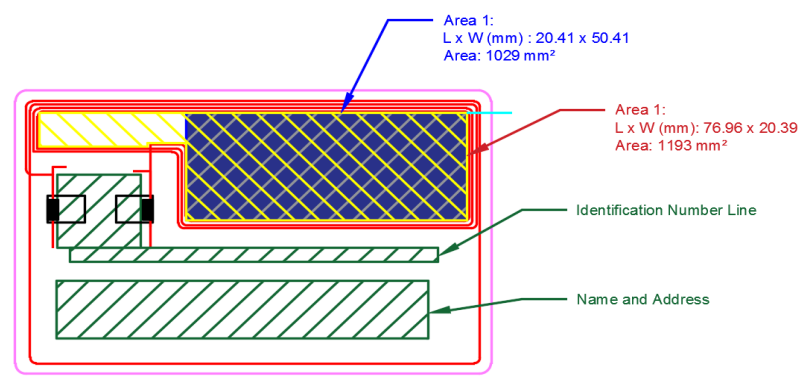

Fig. 2. Graphical Representation of Area Allocation for RFID UHF Tag

The layout of UHF tag antenna is shown in Fig.3 with dimensions of $17.90 \times 49.14 \mathrm{~mm}^{2}$. The design is simulated 
in CST (Computer Simulation Tool) using aluminium with conductivity of $3.56 \times 10^{7} \mathrm{~S} / \mathrm{m}$ and the thickness of 0.01 $\mathrm{mm}$ on PET due to mechanical flexibility and high electrical performance. The thickness of PET substrate is $0.05 \mathrm{~mm}$ with relative permittivity of $\epsilon_{r}=3$ [8] and dielectric loss tangent of 0.021 . The dimensions of the inductive loop are designed to match the tag antenna imaginary impedance with the imaginary part of chip, while the design of UHF tag with meander lines and bent edges are made to match the real impedance with chip. The rectangular bars are introduced on all sides of the design to shift the resonance frequency to European frequency band region. The length and width of the meander structure are optimized after performing parametric analysis and simulations, the optimum dimensions are achieved and shown in TABLE3.

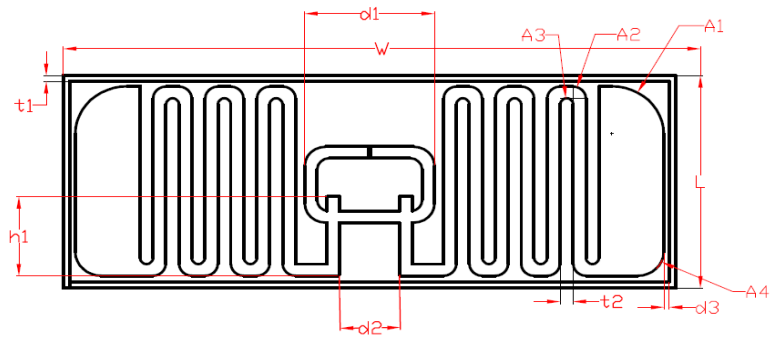

Fig. 3. UHF Tag Antenna Layout

TABLE III

DIMENSIONS OF UHF TAG

\begin{tabular}{|c|c|}
\hline Parameters & Dimensions \\
\hline $\mathrm{L}$ & 17.90 \\
\hline $\mathrm{W}$ & 49.14 \\
\hline $\mathrm{t} 1$ & 0.5 \\
\hline $\mathrm{t} 2$ & 1.0 \\
\hline $\mathrm{h} 1$ & 6.70 \\
\hline $\mathrm{d} 1$ & 10.01 \\
\hline $\mathrm{d} 3$ & 0.41 \\
\hline $\mathrm{d} 2$ & 4.63 \\
\hline $\mathrm{A} 1$ & 4 degree \\
\hline $\mathrm{A} 2$ & 1 degree \\
\hline $\mathrm{A} 3$ & 0.5 degree \\
\hline $\mathrm{A} 4$ & 2 degree \\
\hline
\end{tabular}

\section{Results And Discussion}

The simulated $\mathrm{S}$ parameters are shown in Fig.4. It can be seen that the UHF tag is resonating at $865.8 \mathrm{MHz}$ with $S_{11}=-$ $30.71 \mathrm{~dB}$. The half power beam width (reflection coefficient $<-$ $3 \mathrm{~dB}$ ) is almost $8 \mathrm{MHz}$ covering the whole European frequency band region. While, Fig.5 is showing the omni-directional radiation pattern of UHF tag antenna in free space with the computed peak gain of around $1.7 \mathrm{~dB}$ at $866 \mathrm{MHz}$.

From simulated results, $Z_{\text {ant }}=12.88+j 127.68 \Omega$ which shows a good agreement with 7 . The theoretical read range of UHF tag is calculated as $12.66 \mathrm{~m}$ by using equation 2

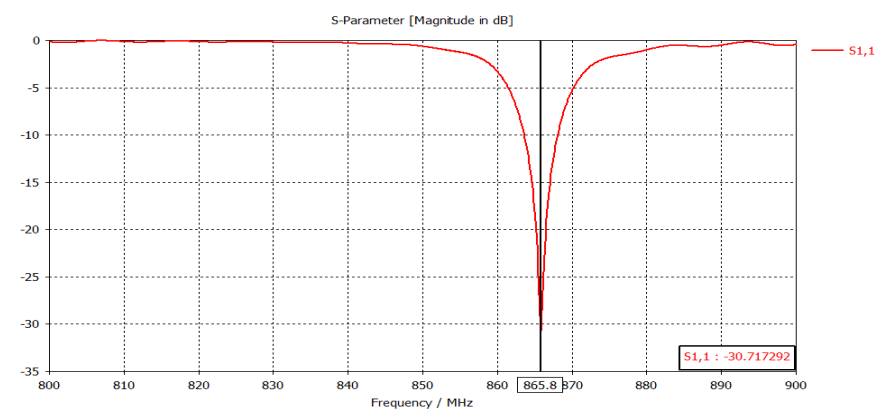

Fig. 4. Power Reflection Coefficient

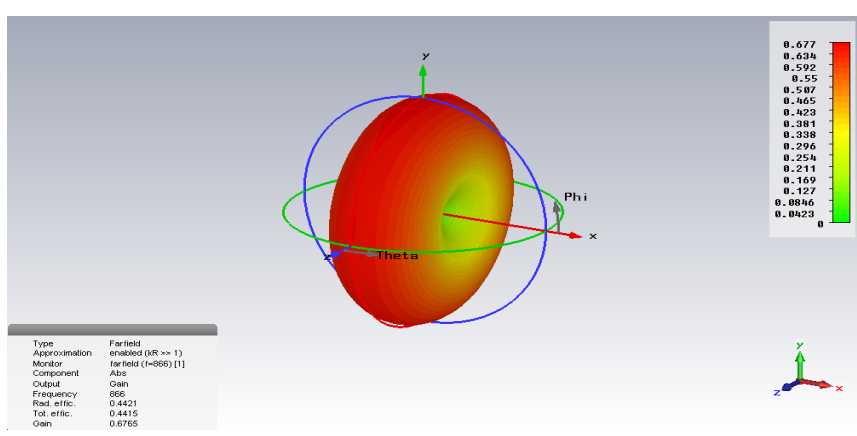

Fig. 5. Radiation Pattern of UHF Tag Antenna in Free Space

and 3. The Effective Isotropic Radiated Power (EIRP) has the maximum value allowed by European Telecommunications Standards Institute (ETSI) is EIRP $=3.3$ Watts. The simulated gain of the $\operatorname{tag} G_{R}=1.7 d B$ and transmitted power by the reader $P_{T}=-20 \mathrm{dBm}$.

TABLE IV

Comparison of Proposed UHF Tag with Previous Published WORK

\begin{tabular}{|c|c|c|c|c|}
\hline Parameters & $\begin{array}{c}\text { Dimensions } \\
\mathrm{mm}^{2}\end{array}$ & $\begin{array}{c}\text { Reflection Coefficient } \\
S_{11}\end{array}$ & $\begin{array}{c}\text { Read Range } \\
\mathrm{m}\end{array}$ & $\begin{array}{c}\text { Gain } \\
\mathrm{dB}\end{array}$ \\
\hline$[13]$ & $91 \times 27$ & -14.5 & 7.32 & 1.75 \\
\hline$[14]$ & $84.6 \times 28$ & -35 & 6.2 & 1.8 \\
\hline$[15]$ & $77.33 \times 77.4$ & -12.75 & 6.47 & 1.97 \\
\hline$[16]$ & $78 \times 30$ & -20 & 5 & 1.11 \\
\hline Proposed design & $49.14 \times 17.90$ & -30.71 & 12.66 & 1.7 \\
\hline
\end{tabular}

TABLE4 is showing the comparison of the proposed UHF tag design in terms of dimensions, reflection coefficient, read range and gain with previous published work. It can be seen that the proposed design is much smaller in dimensions with very good reflection coefficient values with high antenna gain and read range.

\section{CONClusion}

In this paper, we have presented a novel design of UHF RFID tag antenna using PET substrate and aluminium as the metallic track. This antenna has small size as compared to most of the previous work done in literature. It can be easily fit in limited space of bank cards for introducing tracking feature along with EMV chip and contact less payment facility. The 
simulated reflection coefficient is $-30.71 \mathrm{~dB}$ at $865.8 \mathrm{MHz}$ with the bandwidth of $8 \mathrm{MHz}$. The gain of the proposed tag antenna is $1.7 \mathrm{~dB}$ with computed maximum read range of $12.66 \mathrm{~m}$. It can be adopted in other wireless applications with the ability to operate at European frequency band region.

\section{ACKNOWLEDGEMENT}

This work has been carried out as a part of the Innovate UK funded research project in collaboration with London South Bank University and Reward Technology. The Authors are grateful to the Reward technology team for providing support throughout the project.

\section{REFERENCES}

[1] K. Finkenzeller, RFID handbook: fundamentals and applications in contactless smart cards, radio frequency identification and near-field communication. John Wiley \& Sons, 2010.

[2] L. Yang, A. Rida, and M. M. Tentzeris, "Design and development of radio frequency identification (rfid) and rfid-enabled sensors on flexible low cost substrates," Synthesis Lectures on RF/Microwaves, vol. 1, no. 1, pp. 1-89, 2009.

[3] Y. Ma, R. Abd-Alhameed, D. Zhou, C. See, Z. Abidin, C. Jin, and B. Peng, "Loop feed meander-line antenna rfid tag design for uhf band," in General Assembly and Scientific Symposium (URSI GASS), 2014 XXXIth URSI. IEEE, 2014, pp. 1-4.

[4] H. Lehpamer, RFID design principles. Artech House, 2012.

[5] K. S. Rao, P. V. Nikitin, and S. F. Lam, "Impedance matching concepts in rfid transponder design," in Automatic Identification Advanced Technologies, 2005. Fourth IEEE Workshop on. IEEE, 2005, pp. 39-42.

[6] J. Alarcón, T. Deleruyelle, P. Pannier, and M. Egels, "A new spiral antenna for passive uhf rfid tag on different substrates," in Antennas and Propagation (EuCAP), 2010 Proceedings of the Fourth European Conference on. IEEE, 2010, pp. 1-4.

[7] Y. Lee, C. H. Kim, D.-Y. Shin, and Y. G. Kim, "Printed uhf rfid antennas with high efficiencies using nano-particle silver ink," Journal of nanoscience and nanotechnology, vol. 11, no. 7, pp. 6425-6428, 2011.

[8] G. A. Casula, G. Montisci, and G. Mazzarella, "A wideband pet inkjetprinted antenna for uhf rfid," IEEE Antennas and Wireless Propagation Letters, vol. 12, pp. 1400-1403, 2013.

[9] A. E. Abdulhadi and R. Abhari, "Design and experimental evaluation of miniaturized monopole uhf rfid tag antennas," IEEE Antennas and Wireless Propagation Letters, vol. 11, pp. 248-251, 2012.

[10] M. A. Ziai and J. C. Batchelor, "Temporary on-skin passive uhf rfid transfer tag," IEEE Transactions on Antennas and Propagation, vol. 59, no. 10 , pp. 3565-3571, 2011.

[11] T. G. L. of Business, "Regulatory status for using rfid in the epc gen2 ( 860 to $960 \mathrm{mhz}$ ) band of the uhf spectrum," The Global Language of Business, 2016.

[12] Impinj, "Monza r6 datasheet," Monza R6 UHF RFID tag chip, 2014.

[13] T.-W. Koo, D. Kim, J.-I. Ryu, H.-M. Seo, J.-G. Yook, and J.-C. Kim, "Design of a label-typed uhf rfid tag antenna for metallic objects," IEEE Antennas and wireless propagation letters, vol. 10, pp. 1010-1014, 2011.

[14] A. Ennajih, J. Zbitou, A. Errkik, A. Tajmouati, L. El Abdellaoui, and M. Latrach, "A novel design of passive uhf rfid tag antenna mounted on paper," in Wireless Technologies, Embedded and Intelligent Systems (WITS), 2017 International Conference on. IEEE, 2017, pp. 1-6.

[15] A. M. Salama and K. M. Quboa, "A new fractal loop antenna for passive uhf rfid tags applications," in Information and Communication Technologies: From Theory to Applications, 2008. ICTTA 2008. 3rd International Conference on. IEEE, 2008, pp. 1-6.

[16] H. Kimouche and H. Zemmour, "A compact fractal dipole antenna for $915 \mathrm{mhz}$ and $2.4 \mathrm{ghz}$ rfid tag applications," Progress In Electromagnetics Research Letters, vol. 26, pp. 105-114, 2011. 